\title{
Porcine urinary bladder extracellular matrix activates skeletal myogenesis in mouse muscle cryoinjury
}

\author{
Juquan Song ${ }^{1 *}$, Peter Hornsby ${ }^{2}$, Morgan Stanley ${ }^{3}$, Kareem R. AbdelFattah ${ }^{1}$ and Steven E. Wolf \\ *Correspondence: Juquan.Song@UTSouthwestern.edu

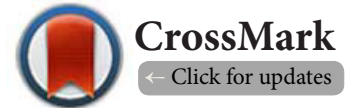 \\ 'Department of Surgery, University of Texas-Southwestern Medical Center, Dallas, TX, USA. \\ ${ }^{2}$ South Texas Veterans Health Care System, Department of Physiology, USA. \\ ${ }^{3}$ Department of Surgery, University of Texas Health Science Center at San Antonio, TX, USA.
}

\begin{abstract}
Background: Accelerated muscle regeneration is highly desirable after direct injury in trauma patients. Though the advantage of extracellular matrix extracted from porcine urine bladder (UBM) on tissue regeneration is feasible, the mechanisms by which skeletal myogenesis is improved are not clear. The current study aim was to determine whether UBM affects skeletal satellite cells during muscle repair after cryoinjury.

Methods: RAG2 ${ }^{-1}, \gamma \mathrm{c}^{-/}$mice underwent bilateral gluteus muscle cryoinjury under general anesthesia. 200 $\mu \mathrm{g}$ UBM suspended in $20 \mu \mathrm{l}$ of Matrigel solution was implanted on one side of the wound intramuscularly, and $20 \mu \mathrm{l}$ of vehicle was applied on the contralateral side as a sham treatment. Five animals without any operation served as baseline. Mice were sacrificed from days 1 to 28 after injury for muscle tissue collection. Tissue morphology was estimated via H\&E staining. Satellite cell proliferation was examined by immunofluorescence staining and western blot. Myogenesis markers were assessed by qPCR.

Results: H\&E staining results showed that muscle regeneration area increased in both sham and UBM treated muscles following injury. The number of regenerating myotubes was significantly higher in UBM treated tissue at 28 days ( $<<0.05$, vs. sham group). Both Pax $7^{+}$and $\mathrm{Ki}-67^{+}$satellite cell number significantly increased in muscle with UBM treatment compared to sham treated muscles $(\mathrm{p}<0.05)$. Protein levels of proliferating cell nuclear antigen (PCNA) were greater in muscle with UBM treatment at day 14 and $28(\mathrm{p}<0.05)$. MyoD1 and myogenin mRNA levels were also significantly higher in UBM treated animal muscle at day 28 $(\mathrm{p}<0.05)$.

Conclusion: UBM treatment increased skeletal satellite cell proliferation and myogenic differentiation at 28 days after local muscle injury.

Keywords: Skeletal muscle injury, muscle regeneration, satellite cell, proliferation, differentiation
\end{abstract}

\section{Introduction}

Skeletal muscle represents the largest tissue mass in the body, consisting of $40 \%$ to $45 \%$ of total body weight and is responsible for supportive and locomotive functions [1]. This tissue is at risk for injury whether purposeful (exercise) [2] or in traumatic incidents. In the case of exercise, regeneration of the injured tissue is the desired response, and for direct injury from trauma this is also true. However, after direct injury the muscle mass is lost with minimal regeneration affecting long term recovery and function. Current clinical management options include functional free muscle transfer and the use of advanced bracing [3], which have limited efficiency on muscle recovery. Improvement of muscle regrowth is then of major concern in the treatment of those with severe and direct muscle injury.

Muscle regeneration involves both resident and non-resident cells with myogenic properties. The major participants in adult muscle regeneration are muscle satellite cells which reside underneath the basal lamina of mature muscle fibers.
In response to skeletal muscle injury, quiescent satellite cells (SCs) are activated to become myogenic precursor cells (MPC) or myoblasts, and begin to proliferate [4]. Under certain conditions, some activated myoblasts cease proliferation and start differentiation. They fuse to form myotubes characterized by centrally located nuclei. The regulation of this process is complicated with involvement of pair box protein Pax 3 and Pax7 in myogenic activation. Myogenic cell differentiation is regulated by myogenic regulatory factors (MRFs) such as MyoD1, myogenin, herculin (MRF 4) and myf5. Associated with expression of these mediators, myoblasts form new myotubes through the steps of differentiation and maturation, and eventually, satellite cells generate new myotubes that fuse with existing myofibers to augment and repair damaged muscle [5].

Regenerative medicine utilizes new and old scientific techniques, and discoveries in this arena hold the promise for advances in muscle regeneration [6]. This field studies the development and regeneration of cells, tissues, and organs by using pluripotent cells, biomaterials scaffolds, and bioreagents 
such as growth factors with the aim of recovering body function, and have been applied in clinical studies of skeletal muscle regeneration in trauma patients [7-9]. A side from the viability of the cell itself, the extracellular environment is considered one of the most important factors for cell growth into functional tissue. Extracellular matrix provides a microenvironment for cell growth and differentiation based on its structure, and content of factors that assist cell migration, localization, and differentiation [10].

A type of extracellular matrix derived from decellularized porcine urinary bladder mucosa [11] has been shown to improve different types of tissue regeneration in vivo $[12,13]$. UBM contains over $90 \%$ type I, III, IV and V collagens with other components including glycosaminoglycans (GAG), transforming growth factor, basic fibroblast growth factor, vascular endothelial growth factor. Beattie et al., reported that UBM treatment improved tendon repair, which is associated with chemotaxis of multipotential progenitor cells to the wound site [14], and this benefit might be the result of bioactive components released from UBM [15].

A recent clinical case reported robust improvement of muscle mass and function recovery with porcine derived extracellular matrix treatment in a volumetric muscle loss (VML) trauma patient [16]. Comparing the data obtained 5 months prior to UBM implantation and 9 months after, muscle mass increased by $15 \%$ and muscle function over $20 \%$ via leg extension torque test. However, the underlying mechanism of the action of UBM was not fully understood. As a potential explanation, we wonder whether that UBM improves muscle regeneration after injury through augmented myogenic pro-genitor cell proliferation and differentiation. Thus, the aim of this study was to investigate the effect of UBM on skeletal satellite cell regulation after local injury. Application of a liquid nitrogen cooled probe caused a well-defined discshaped cryolesion. This technique has been used repeatedly for related experiments in myocardial $[17,18]$, smooth muscle [19], and skeletal muscle injuries [20]. Using this model, we found that UBM treatment has a positive effect on satellite cell proliferation and differentiation following a local injury.

\section{Methods}

\section{Animal experiments}

Homozygous immunodeficient mice (strain RAG2 $2^{-1-}, \mathrm{Yc}^{--}$) originally purchased from Taconic (Germantown, NY) were maintained in an animal barrier facility as a breeding colony. All animal procedures were performed in adherence to the National Institutes of Health Guide for the Care and Use of Laboratory Animals and were approved by the Institutional Animal Care and Use Committee of the University of Texas Health Science Center at San Antonio, TX.

Thirty-five male mice (8 to 12 weeks old) were anesthetized with avertin $(250 \mathrm{mg} / \mathrm{kg}$ of body weight) intraperitoneally. Under general anesthesia, mice were shaved on the lower dorsal surface. Skin was then incised along the midline and the gluteus maximus muscle was exposed. A $30.5 \mathrm{~cm}$ long copper probe with an oval shape end $(4 \times 6 \mathrm{~mm})$ was immersed into liquid nitrogen before each injury. The pre-cooled probe end was directly applied on the gluteus maximus muscle bilaterally for twenty seconds to induce

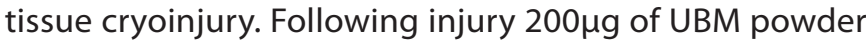
(ACell, Columbia, MD) suspended in $20 \mu$ l of $50 \%$ Matrigel solution (BD science, San Jose, California), was injected into the center of the injured muscle using a $1.3 \mathrm{~cm} 25 \mathrm{G}$ gauge blunt needle and $50 \mu \mathrm{l}$ glass Hamilton syringe (Hamilton Co., Reno, NV); and $20 \mu$ l of $50 \%$ Matrigel solution without UBM into the contralateral muscle. The skin incision was closed with surgical staples. Animals were allowed to fully recover on a $35^{\circ} \mathrm{C}$ ambient temperature padding and housed individually with acetaminophen supplied in the drinking water $(1 \mathrm{mg} / \mathrm{ml})$. At days 1, 3, 7, 14 and 28 after injury, animals were sacrificed ( $n=7 /$ time point) and the gluteus muscle, including gluteus maximus, gluteus medius and gluteus minimus muscle were harvested. Muscle tissues was weighed and bisected through the wound center. One half of the sample was fixed in $4 \%$ fresh paraformaldehyde (PFA) for histological processing; and the other half was snap-frozen in liquid nitrogen and stored in $-70^{\circ} \mathrm{C}$ for molecular analysis. Five mice without any interventions served as a control group.

\section{Tissue histomorphology with hematoxylin \& eosin (H\&E) staining}

The muscle tissues were fixed overnight in 4\% PFA in 0.1M Phosphate Buffer (PFA) and paraffin embedded as described previously [21]. Paraffin blocks were sectioned, and five cross-sectional planes were acquired from the center of the injury site to the wound edge at $40 \mu \mathrm{m}$ intervals in order to determine the center of the lesion. Tissue sections $(5 \mu \mathrm{m})$ were deparaffinized and rehydrated using graded alcohol concentrations followed by H\&E staining method. The image of the entire cross sectional plane was captured by using a Nikon Eclipse 6400 light microscope equipped with a Photometrics Colorsnap CF camera, computer controlled with RS image software (Photometrics, Tucson, AZ). Cells with centrally located nuclei were considered as regenerating myoblast and myotubes. Nuclei with no discernible surrounding cytoplasm were not counted. Muscle tissue damage and regenerating areas were measured and the number of regenerating myotube was counted by a blinded observer.

\section{Immunofluorscent staining}

$5 \mu \mathrm{m}$ tissue sections were deparaffinized, rehydrated in graded alcohol and washed with PBS buffer. Sections were then immersed into sodium citrate buffer $(10 \mathrm{mM}$ sodium citrate, $0.05 \%$ Tween 20, pH 6.0) and heated for 30 minutes for antigen retrieval. After blocking with $10 \%$ goat serum for 60 minutes, sections were incubated with either 1:20 of Pax7 primary antibody (Santa Cruz Tech, Santa cruz, CA) followed by 1:500 Cy3 anti-mouse IgG, (Jackson Immuno Research 
Laboratories, West Grove, PA) or 1:300 of Ki-67 primary antibody (Millipore, Billerica, MA) with1:500 Alexa Fluor 594 Goat Anti-Rabbit IgG (Invitrogen, Carlsbad, CA) and1:500 Alexa Fluor 488 phalloidin (Invitrogen, Carlsbad, CA). Sections were added $25 \mu$ l of ProLong Gold anti-fade reagent with DAPI nuclear staining (Invitrogen, Carlsbad, CA) before coverslip mounting. Five images were obtained for each slide with a Nikon Eclipse TE2000-U microscope with CCD camera under $40 \mathrm{X}$ objective. The numbers of $\mathrm{Pax} 7^{+}$cell and $\mathrm{Ki}-67^{+}$cell were counted by a blinded observer.

\section{Western blot}

$25 \mathrm{mg}$ of muscle tissue was homogenized in $150 \mathrm{mM} \mathrm{NaCl}$, 50 mM Tris-HCl, pH 7.8, 1\% (w/v) Triton X-100, 1 mM EDTA, 0.5 $\mathrm{mM}$ phenylmethanesulfonyl fluoride, $1 \mathrm{X}$ Complete protease inhibitor mixture (Thermo Fisher Scientific Inc., Waltham, MA) and a phosphatase inhibitor cocktail (Sigma-Aldrich, St. Louis, MO). The homogenate was centrifuged at $20,000 \mathrm{xg}$ for 30 minutes at $4^{\circ} \mathrm{C}$ and the pellet discarded. Twenty micrograms of each protein sample was subsequently analyzed by SDS-PAGE and western blot. Proliferating cell nuclear antigen (PCNA) and glyceraldehyde 3-phosphate dehydrogenase(GAPDH) antibodies were purchased from Cell Signaling Tech, Inc. (Danvers, MA). SuperSignal West Pico Chemiluminescent Substrate was purchased from Thermo Scientific Inc, (Rockford, IL). Band intensities were quantified with the GeneSnap/ GeneTools software (Syngene, Frederick, MD).

\section{Quantitative PCR}

Total RNA was extracted from $25 \mathrm{mg}$ of tissue using RNeasy Fibrous tissue mini kit (Qiagen, Valencia, CA). RNA yield was measured using a NanoDrop 3300 Fluorospectrometer (Thermo Fisher Scientific Inc, Wilmington, DE). One microgram of RNA sample was incubated with 250ng of random primers

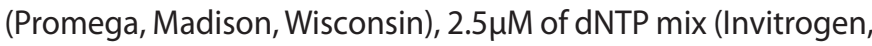
Carlsbad, CA) and 50 units of superscript RT transcriptase (Invitrogen, Carlsbad, CA) to make a cDNA template. Real time quantitative PCR (qPCR) was performed with standard curve method using $A B I 7900 \mathrm{HT}$ fast real-time PCR system installed with SDS 2.4 standalone software (A\&B Applied Biosystems, Carlsbad, CA). Gene expressions of MRFs including MyoD1 and myogenin were examined. Primers were designed using Primer-BLAST (NCBI) (Table 1). GAPDH was used as a

Table 1. Mouse specific primer sequences for qPCR analysis.

\begin{tabular}{|c|c|c|c|}
\hline Target Gene & $\begin{array}{l}\text { NCBI Reference } \\
\text { Sequence }\end{array}$ & $\begin{array}{l}\text { Forward primer, } \\
\text { Oligo sequence } \\
\text { (5' to 3') }\end{array}$ & $\begin{array}{l}\text { Reverse primer, Oligo } \\
\left.\text { sequence (5' to } 3^{\prime}\right)\end{array}$ \\
\hline MyoD1 & NM_010866.2 & $\begin{array}{l}\text { ACGACT- } \\
\text { GCTTTCTTCAC- } \\
\text { CACTCCT }\end{array}$ & $\begin{array}{l}\text { TCGTCTTA- } \\
\text { ACTTTCTGC- } \\
\text { CACTCCG }\end{array}$ \\
\hline Myogenin & NM_031189.2 & $\begin{array}{l}\text { ACAGCATCACG- } \\
\text { GTGGAGGATATGT }\end{array}$ & $\begin{array}{l}\text { CCCTGCTA- } \\
\text { CAGAAGTGATG- } \\
\text { GCTTT }\end{array}$ \\
\hline GAPDH & XM_001479371.3 & $\begin{array}{l}\text { ACCCCCAATG- } \\
\text { TATCCGTTGT }\end{array}$ & $\begin{array}{l}\text { TACTCCTTGGAG- } \\
\text { GCCATGTA }\end{array}$ \\
\hline
\end{tabular}

reference gene. Relative quantitation of target mRNA levels was performed by the $2^{-\mathrm{DDCt}}$ method.

\section{Statistical analysis}

Statistical analyses were performed by Sigma Plot 12 software (Systat Software, Inc, San Jose, CA) using one-way analysis of variance with Bonferroni t-test or paired t-test where appropriate. Data were reported with mean and standard error of the mean (SEM). Significance of statistical results was accepted with an a priori a of 0.05 .

\section{Results}

Time course of histological changes after cryoinjury H\&E stained slides demonstrated that muscle tissue was damaged after injury, as evidenced by cell swelling, sarcolemma destruction, disappearance of skeletal muscle striated structures, and neutrophil/macrophage infiltration into the lesion area starting on day 1 after injury. Regenerating myoblasts and myotubes with centrally located nuclei appeared at day 7 and then migrated to the center of the wound. At day 28 , myotubes occupied the wound site in the muscle and crossed with newly formed myofibers (Figure 1). The area of the lesion in the tissue cross section plane reached a peak at day 3 after injury $\left(9.14 \pm 0.69 \mathrm{~mm}^{2}\right.$ in injury group; $8.33 \pm 0.84 \mathrm{~mm}^{2}$ in UBM group) and declined afterwards in both groups; while the area of regenerating myotubes were increased day 7 after injury $\left(1.37 \pm 0.43 \mathrm{~mm}^{2}\right.$ in injury group \& $1.52 \pm 0.76 \mathrm{~mm}^{2}$ in UBM group at day $7 ; 4.19 \pm 0.24 \mathrm{~mm}^{2}$ in injury group \& $4.14 \pm 0.78 \mathrm{~mm}^{2}$ in UBM group at day 14 ). We did not observe muscle histological differences between UBM and sham treatment until after day 14 from injury. Interestingly, the regenerating myotube number significantly increased in muscle tissue at day 28 with UBM treatment compared to sham treatment $(p<0.05)$ (Figure 2).

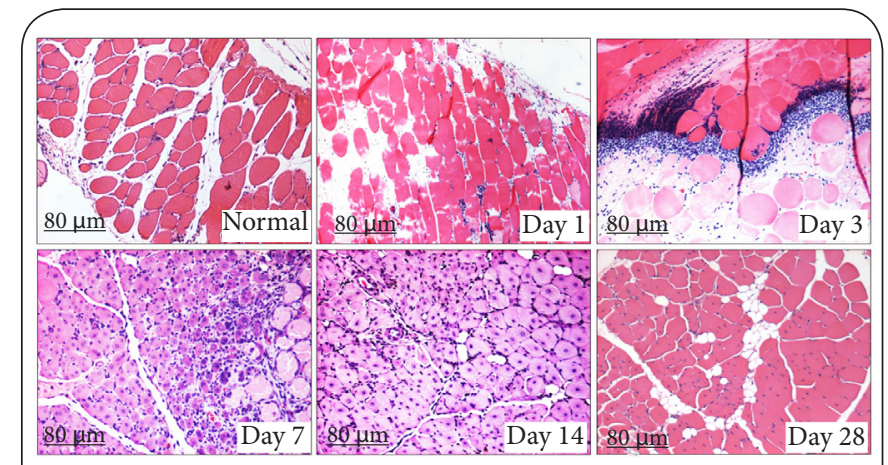

Figure 1. Histologic morphology of gluteus muscle from day 1 to 28 after injury. Muscle tissue was H\&E stained and examined under a light microscope.

Satellite cell activation and proliferation increased with UBM treatment after injury

Paired box protein Pax7 is a recognized marker of satellite cells. 


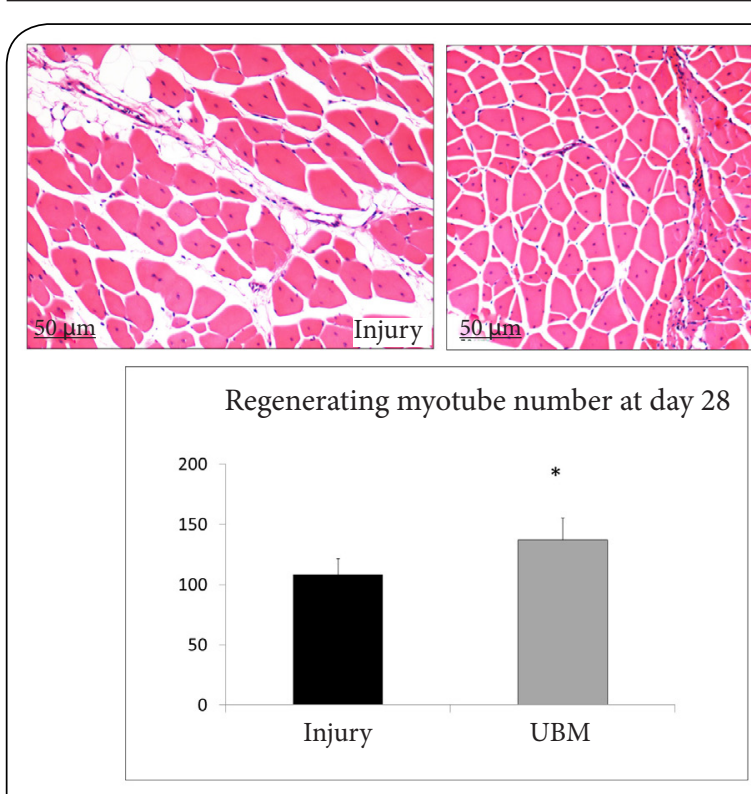

Figure 2. H\&E stained tissue slides from sham treatment (Injury) and UBM treatment (UBM) at 28 days after injury and statistics results of regenerating myotube number. Myotube was considered as a developing muscle cell with one or multiple, centrally-located nucleuses, muscle cell without centrally-located nucleus was not counted. Value was presented as mean \pm SEM. ${ }^{\star} \mathrm{p}<0.05$, UBM treatment group vs. Injury sham group.

It is expressed in both quiescent activated satellite cells and gradually decreases with maturation to new myofibers [22]. The double immunofluorescent staining results showed that $\mathrm{Pax}^{+}$myocytes overlapped with DAPI blue stained nuclear and resided between the basal lamina and sarcolemmain normal mouse muscle tissue (Figure $3 \mathrm{~A}$ ). The number of Pax $7^{+}$ satellite cell significantly increased in gluteus muscle at day 1 after injury, $(p<0.05)$ and gradually decreased after reaching the peak at day 3. The number of $\mathrm{Pax} 7^{+}$satellite cell increased continually in muscle with UBM treatment during the time of course of experiment, and there were significant differences in muscles between UBM and sham treatment at day 7 and day $28(p<0.05)$ (Figures 3B and $3 C$ ).

$\mathrm{Ki}-67$ is a nuclear protein that is associated with cellular proliferation. We found that $\mathrm{Ki}-67^{+}$satellite cell was red stained and localized between the base membrane and the edge of sarcolemma in muscle tissue (Figure 4A). The number of $\mathrm{Ki}$ $67^{+}$satellite cells in gluteus muscle decreased at day 1 after injury ( $p<0.05$, vs. normal control). The number of Ki- $67^{+}$cell was significant higher in muscle tissue with UBM treatment than that of vehicle treatment at day 14 and $28(p<0.05)$ (Figures 4B and 4C). To follow up the immunofluorescent data, we examined another cell proliferation maker proliferating cell nuclear antigen (PCNA). Western blot results showed that the ratio of PCNA to GAPDH was significantly higher in the

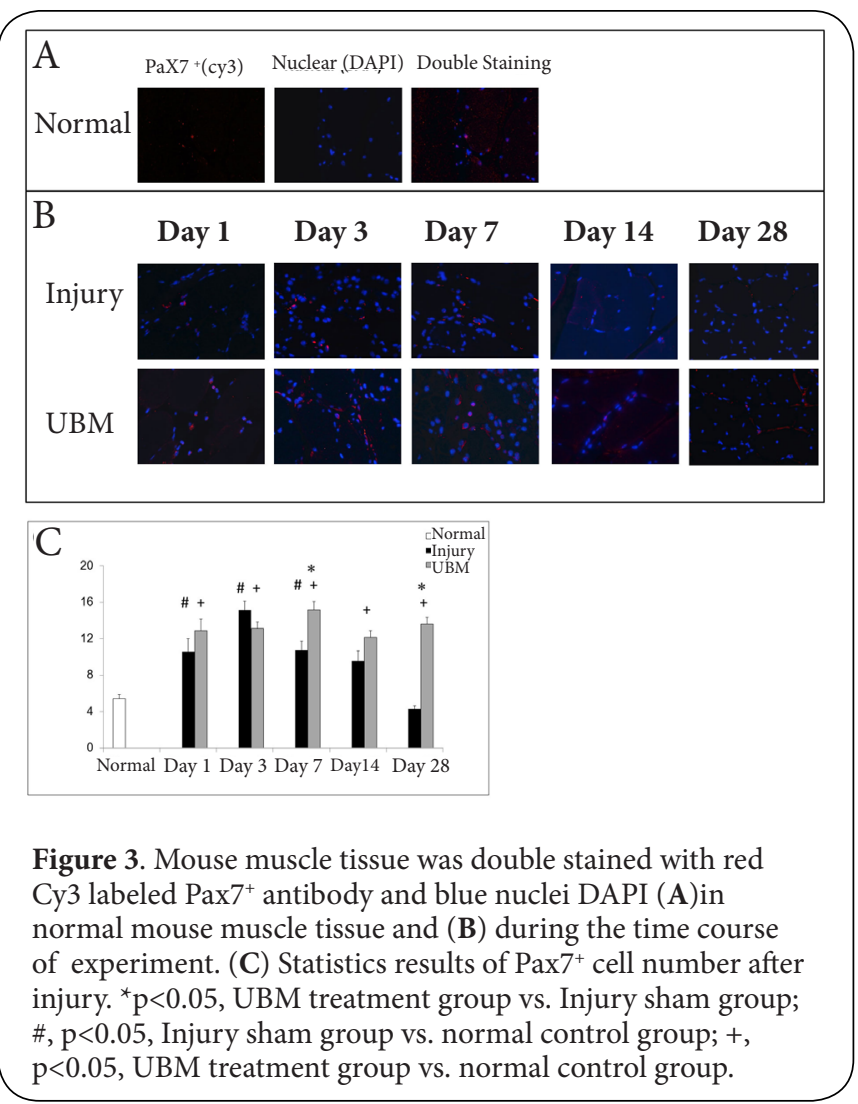

muscle tissue from UBM treated than those from sham treated at day 14 and day 28 after injury ( $p<0.05$ ) (Figures 4D and 4E).

Myogenic progenitor cell differentiation in mice gluteus muscle after cryoinjury

Myogenic differentiation markers MyoD1 and myogenin both mRNA levels significantly increased at day 3 and 7after injury $(p<0.05)$. The expression of MyoD1 reached peak levels earlier at day 3 in both UBM and sham treatment groups; while the expression of myogenin gradually increased and reached the highest level at day 7 in both groups. Although MyoD1 and myogenin decreased day 7 after injury, the levels of MyoD1 and myogenin were significantly higher in muscle tissue with UBM treatment at day 28 after injury (Figures 5A and 5B) MyoD gene expression was confirmed with its protein level. Western blot data showed that the absorbance ratio of MyoD1 to GAPDH was significantly greater in injured muscle with UBM treatment at day $28(p<0.05)$ (Figure 6).

\section{Discussion}

In the current study, we showed that myogenic progenitor cells activated and differentiated in gluteus muscle during muscle regeneration following local cryoinjury. Furthermore, we found that UBM treatment improved satellite cell activation and differentiation and thus augmented skeletal myogenesis 

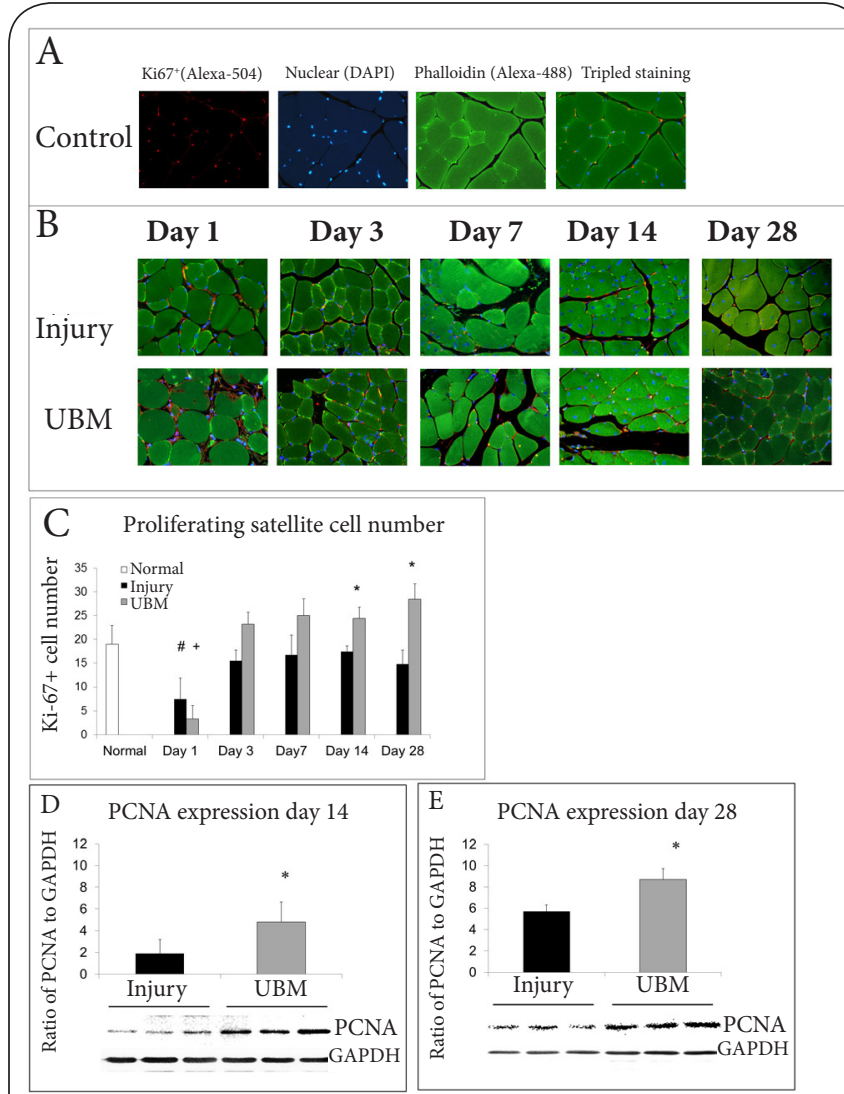

Figure 4. Satellite cell proliferation was assessed by immunofluorescent staining and western blot. (A) Ki$67^{+}$cells labeled with Alexa-594 were localized between the basement membrane and sarcolemma (red stained), myonuclei were blue stained with DAPI, and scaroplasma stained with Alexa-488conjugated phalloidin from normal animals; (B) Merged triple staining images from animals with injury (upper) and UBM (lower) groups; and (C) Statistics description of the number of $\mathrm{Ki}-67^{+}$satellite cell after injury. Western blot data and statistics analysis showed that the expression of PCNA and GAPDH in animal muscle tissue (D) at day 14 and (E) day 28 after injury. ${ }^{*} \mathrm{p}<0.05$, UBM treatment group vs. Injury sham group; \#, $p<0.05$, Injury sham group vs. normal control group;,$+ \mathrm{p}<0.05$, UBM treatment group vs. normal control group.

with accrual of myotube within a month of injury.

Muscle regeneration starts after an injury. A time course study showed that muscle enzymes (creatine kinase and lactate dehydrogenase) were maximally decreased in muscle tissue lysate within 3 days and returned to baseline levels by day 14 , which is consistent with injury and regeneration observed by histology [23]. In the current animal model, we also observed the similar pattern of skeletal myogenesis following the local cryoinjury. Muscle histomorphology in this study showed that muscle regeneration with myoblast and myotube appearance at day 7 following the muscle tissue damage.

The RAG2 $2^{-1-} \gamma \mathrm{c}^{--\gamma}$ double mutant mice are completely de-
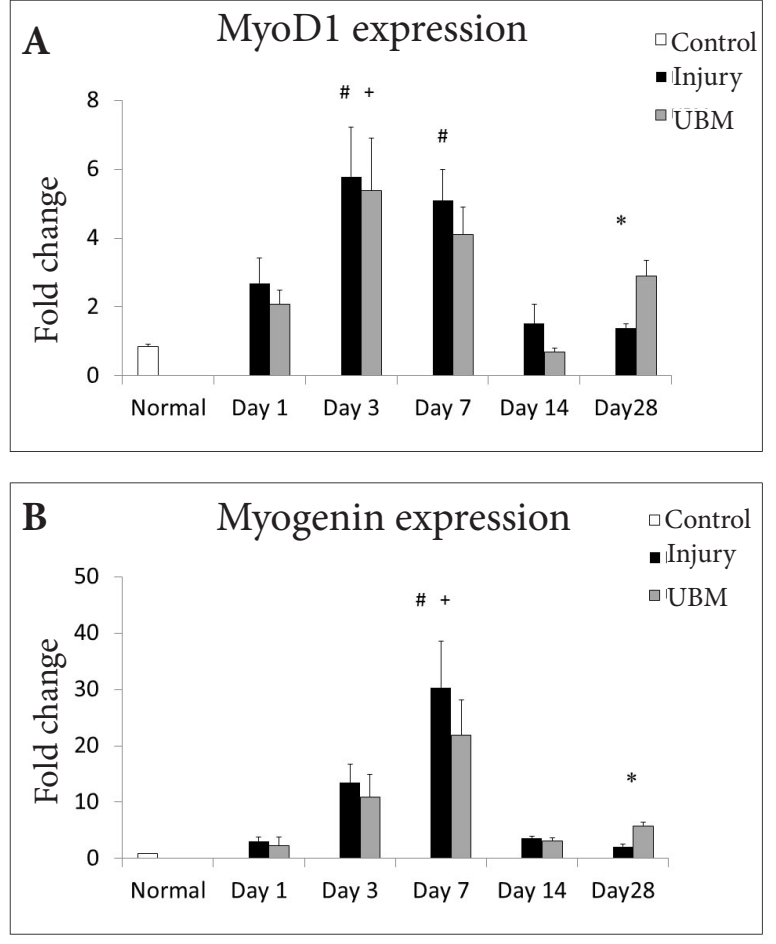

Figure 5. Myogenesis markers (A) MyoD1 and (B) myogenin expressed in mouse muscle tissue after injury from day 1 to day 28. Gene expression level was detected by real-time qPCR. The fold change of target gene was presented as mean \pm SEM. ${ }^{*} \mathrm{p}<0.05$, UBM treatment group vs. Injury sham group; \#, $\mathrm{p}<0.05$, Injury sham group vs. normal control group;,$+ \mathrm{p}<0.05$, UBM treatment group vs. normal control group.

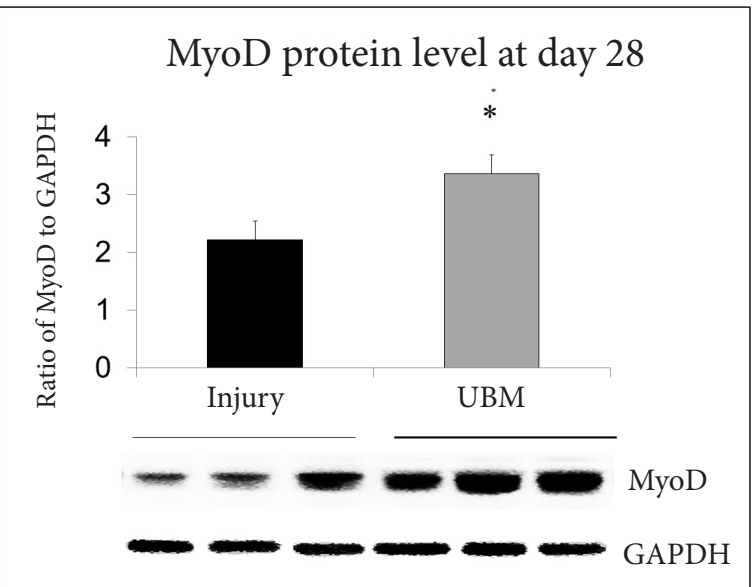

Figure 6. Western blot data and statistics analysis showed that protein levels of MyoD1 and housekeeping protein GAPDH in mouse muscle tissue at 28 after injury. ${ }^{\star} \mathrm{p}<0.05$, UBM treatment group vs. Injury sham group. 
Song et al. Journal of Regenerative Medicine \& Tissue Engineering 2014,

pleted lymphocytes (including T, B and NK cells), but still keep populations of neutrophil and macrophage. Lack of adaptive immune response could affect to determine the role of UBM application in muscle regeneration. Macrophage plays a critical role of regulating muscle cell turn over after injury, especially type II macrophage is beneficial of tissue remodeling and muscle repair [24]. We did not evaluate type I and type II macrophages in response to UBM treatment in this study. The role of macrophage in response to ECM for tissue regeneration and remodeling has been well studied. Badylak in 2008 reported that CD68+ (pan macrophages) mononuclear cells aggregated with implanted biologic scaffolds from porcine small intestinal submucosa (SIS) in rat during the first 4 weeks. Further looking at subpopulation of macrophage, CD163+ positive stained macrophages (M2 profile) were dominated in SIS implantation site and showed constructive remodeling at 16 weeks [25]. In 2009 Brown studied macrophage phenotype in response to UBM in a rat model with abdominal wall muscle defect. Results from gene expression and protein level showed a predominant $\mathrm{M} 2$ type response and resulted in constructive remodeling with acellular UBM implantation; predominantly M1 type was observed in compared group containing a cellular and resulted in deposition of dense connective tissue and/or scarring [26]. In the current model, we observed activation of innate immune response with neutrophil and macrophage infiltration at early time points after cryoinjury. Those similar changes of muscle injury have been shown in wild type mice from Shireman's study [23]. The current animal model can be further developed to optimize muscle regeneration with a combination intervention of human derived stem cell and UBM treatment.

$\mathrm{Pax}^{+}$cell number increased at day 1 after injury indicates that muscle progenitor cell (satellite cell) response to injury stimulation at the earlier stage. MyoD1 is one of the earliest markers of myogenic commitment and play a key role in regulating muscle differentiation. MyoD1 is expressed in activated satellite cells, but not in quiescent satellite cells [27]. Myogenin is a muscle-specific basic-helix-loop-helix (bHLH) transcription factor involved in the coordination of skeletal muscle development and repair. Myogenin was proved to be responsible for the induction of terminal differentiation and activates the expression of skeletal muscle-specific products creatine kinase and myosin heavy chain [28]. In the current study, MyoD1 and myogenin increased at day 3 and day 7 respectively by following the activation of Pax7 at day 1 after injury. Those signal alterations were also compatible to histologic change of regenerated muscle tissue.

The benefit of UBM in muscle regeneration has been reported in several studies. However, there is little information of UBM regulating skeletal satellite cell after injury. Based on satellite cell alteration in response to injury stimulation, we focused the effect of UBM treatment on skeletal myogenesis from day 1 to 28 after injury in the current study. We observed that UBM induced additional satellite cell activation and differentiation, and increased myotube number in muscle regeneration at day 28 after injury. Because we focused on the satellite cell alteration in the current study, we did not examine the effect of UBM longer than day 28 after injury. Based on the current finding, a logical thought is that increased myotube formation should support muscle regeneration with functional recovery evidenced at later time points. Indeed Merritt et al., reported that vascularization and myoblast regeneration started at day 42 after muscle injury with UBM treatment in a rat model [29]. Our results demonstrate that UBM kept activating satellite cells 28 days after injury, which suggests that UBM treatment might improve muscle regeneration at even later than 28 days after injury. We are in the process of extending our observations to later time points with paired functional muscle strength assessments.

Satellite cell is a major resource to initiate muscle regeneration. The current study was to investigate whether UBM mediates muscle progenitor cell satellite cell in muscle regeneration. Many studies revealed stem cells derived from different resource, such as synovial membrane, [30] fat, [31] bone marrow [32] could involve muscle regeneration in muscle repair. Since UBM has been shown to recruit multipotential progenitor cells to the wound site [14], it is a logical thought that other types of multipotential stem cell serve as upstream of muscle progenitor cells and contribute to the mechanism of UBM improving muscle regeneration.

UBM involves tissue regeneration by its own physical structure and bio-active components [33]. Nelson observed the importance of extracellular matrix (ECM) molecules proteoglycans as part of the myogenesis signaling mechanism [34]. Growth factors including TGF- $\beta$, b-FGF and VEGF were found in ECM scaffolds which are critical for tissue regeneration $[35,36]$. More over b-FGF can be preserved its bioactivity in ECM after prolonged storage [37]. Though we focused on the satellite cell alteration within a 28 day period in the current study, a long-term effect study of UBM on skeletal myogenesis in response to injury accompanied with muscle functional recovery test will be consideredin the future.

Myogenesis improvement with UBM treatment is associated with vascularity and innervation present at the site of tissue remodeling. In vitro study showed that UBM supported the attachment and proliferation human microvascular endothelial cell (HMEC). The effect of UBM in vascularization augment has been confirmed for cardiac repair in vivo [38].

An Egypt group reported wound vascularity increased in a full-thickness wound healing study with a combination treatment of keratinocyte and UBM [39]. Badylak et al., found evidence of mature nerve, immature nerve and Schwann cells within the remodeled ECM at 28 days in the rat body wall model, and they further observed that neuronal survival and out growth were supported by the ECM substrate in vitro [40]. Although we focused on muscle cell response to UBM treatment in current study, further investigation of 
neuromuscular junction (expressed with anti-synaptic vesicle protein 2 (anti-SV2) and a-bungarotoxin (a-BuTX)) associated with UBM treatment be considered.

Several animal models have been used to study muscle regeneration. The model of cardiotoxin-induced muscle injury [41] might be more common. However the biologic activities of myotoxin are not fully understood nor is it akin to commonly encountered clinical reasons for muscle loss, and there is little information about its disturbance of UBM effect. There are other methods, including laceration, denervation, and devascularization of muscle to induce muscle regeneration after injury. We chose the cryoinjury model because it is feasible and able to deliver a unified and extensive size of injury consistently. The current injury model had a similar time response pattern of myogenesis compared to other injury models in muscle regeneration study.

In conclusion, UBM application improved satellite cell proliferation and differentiation 28 days after injury. This finding provides potential mechanisms for changes seen with UBM treatment clinically, and provides insight and direction for future study.

\section{List of abbreviations}

UBM: porcine derived extracellular matrix

SCs: satellite cells

MPC: myogenic precursor cells

MRFs: myogenic regulatory factors

QPCR: Real time quantitative PCR

GAPDH: Glyceraldehyde 3-phosphate dehydrogenase

BHLH: basic-helix-loop-helix

PCNA: Proliferating cell nuclear antigen

VML: volumetric muscle loss

PFA: paraformaldehyde

\section{Competing interests}

The authors declare that they have no competing interests.

\section{Authors' contributions}

\begin{tabular}{|l|c|c|c|c|c|}
\hline Authors' contributions & JS & PH & MS & KRA & SEW \\
\hline Research concept and design & $\checkmark$ & $\checkmark$ & -- & -- & $\checkmark$ \\
\hline Collection and/or assembly of data & $\checkmark$ & -- & $\checkmark$ & $\checkmark$ & -- \\
\hline Data analysis and interpretation & $\checkmark$ & $\checkmark$ & -- & -- & $\checkmark$ \\
\hline Writing the article & $\checkmark$ & -- & $\checkmark$ & $\checkmark$ & -- \\
\hline Critical revision of the article & $\checkmark$ & $\checkmark$ & -- & -- & $\checkmark$ \\
\hline Final approval of article & $\checkmark$ & $\checkmark$ & $\checkmark$ & $\checkmark$ & $\checkmark$ \\
\hline Statistical analysis & $\checkmark$ & -- & $\checkmark$ & $\checkmark$ & -- \\
\hline
\end{tabular}

\section{Acknowledgement}

This current study is supported by Elizabeth Huth Coates foundation (\#991556, UTHSCSA) and Department Interim funding (\#47849, UTSW). Authors would thank Anuja Mishra and Zhifang Qiu for animal experiment assistance, MingMei Liu, Kevin Despain and Lisha Ma for immuno histology work.

\section{Publication history}

EIC: W. Scott Argraves, Medical University of South Carolina, USA. Received: 04-Oct-2013 Revised: 25-Jan-2014

Re-Revised: 01-Feb-2014 Accepted: 05-Feb-2014

Published: 27-Feb-2014

\section{References}

1. Beatty $\mathrm{CH}$, Basinger $\mathrm{GM}$ and Bocek RM. Differentiation of red and white fibers in muscle from fetal, neonatal and infant rhesus monkeys. J Histochem Cytochem. 1967; 15:93-103. | Article | PubMed

2. Lehto $M U$ and Jarvinen MJ. Muscle injuries, their healing process and treatment. Ann Chir Gynaecol. 1991; 80:102-8. | PubMed

3. Lin $C H$, Lin YT, Yeh JT and Chen CT. Free functioning muscle transfer for lower extremity posttraumatic composite structure and functional defect. Plast Reconstr Surg. 2007; 119:2118-26. | Article | PubMed

4. Hawke TJ and Garry DJ. Myogenic satellite cells: physiology to molecular biology. J Appl Physiol (1985). 2001; 91:534-51. | Article | PubMed

5. Tedesco FS, Dellavalle A, Diaz-Manera J, Messina G and Cossu G. Repairing skeletal muscle: regenerative potential of skeletal muscle stem cells. J Clin Invest. 2010; 120:11-9. | Article | PubMed Abstract | PubMed Full Text

6. Mason $C$ and Dunnill P. A brief definition of regenerative medicine. Regen Med. 2008; 3:1-5. | Article | PubMed

7. Burd A, Ahmed K, Lam S, Ayyappan T and Huang L. Stem cell strategies in burns care. Burns. 2007; 33:282-91. | Article | PubMed

8. Novikova LN, Novikov LN and Kellerth JO. Biopolymers and biodegradable smart implants for tissue regeneration after spinal cord injury. Curr Opin Neurol. 2003; 16:711-5. | Article | PubMed

9. Schertzer JD and Lynch GS. Comparative evaluation of IGF-I gene transfer and IGF-I protein administration for enhancing skeletal muscle regeneration after injury. Gene Ther. 2006; 13:1657-64. | Article | PubMed

10. van der Kraan PM, Buma P, van Kuppevelt T and van den Berg WB. Interaction of chondrocytes, extracellular matrix and growth factors: relevance for articular cartilage tissue engineering. Osteoarthritis Cartilage. 2002; 10:631-7. | Article | PubMed

11. Brown BN, Barnes CA, Kasick RT, Michel R, Gilbert TW, Beer-Stolz D, Castner DG, Ratner BD and Badylak SF. Surface characterization of extracellular matrix scaffolds. Biomaterials. 2010; 31:428-37. | Article | PubMed Abstract I PubMed Full Text

12. Gilbert TW, Gilbert S, Madden M, Reynolds SD and Badylak SF. Morphologic assessment of extracellular matrix scaffolds for patch tracheoplasty in a canine model. Ann Thorac Surg. 2008; 86:967-74. | Article | PubMed

13. Liu L, Li D, Wang Y, Xu H, Ge L and Liang Z. Evaluation of the biocompatibility and mechanical properties of xenogeneic (porcine) extracellular matrix (ECM) scaffold for pelvic reconstruction. Int Urogynecol J. 2011; 22:221-7. | Article | PubMed

14. Beattie AJ, Gilbert TW, Guyot JP, Yates AJ and Badylak SF. Chemoattraction of progenitor cells by remodeling extracellular matrix scaffolds. Tissue Eng Part A. 2009; 15:1119-25. | Article | PubMed Abstract | PubMed Full Text

15. Reing JE, Zhang L, Myers-Irvin J, Cordero KE, Freytes DO, Heber-Katz E, Bedelbaeva K, McIntosh D, Dewilde A, Braunhut SJ and Badylak SF. Degradation products of extracellular matrix affect cell migration and proliferation. Tissue Eng Part A. 2009; 15:605-14. | Article | PubMed

16. Mase VJ, Jr., Hsu JR, Wolf SE, Wenke JC, Baer DG, Owens J, Badylak SF and Walters TJ. Clinical application of an acellular biologic scaffold for surgical repair of a large, traumatic quadriceps femoris muscle defect. Orthopedics. 2010; 33:511. | Article | PubMed

17. van Amerongen MJ, Harmsen MC, Petersen AH, Popa ER and van Luyn MJ. Cryoinjury: a model of myocardial regeneration. Cardiovasc Pathol. 2008; 17:23-31. | Article | PubMed

18. Murry CE, Whitney ML and Reinecke $H$. Muscle cell grafting for the treatment and prevention of heart failure. J Card Fail. 2002; 8:S532-41. | Article | PubMed

19. Somogyi GT, Yokoyama T, Szell EA, Smith CP, de Groat WC, Huard J and Chancellor MB. Effect of cryoinjury on the contractile parameters of bladder strips: a model of impaired detrusor contractility. Brain Res Bull. 2002; 59:23-8. | Article | PubMed

20. Thaloor D, Miller KJ, Gephart J, Mitchell PO and Pavlath GK. Systemic 
administration of the NF-kappaB inhibitor curcumin stimulates muscle regeneration after traumatic injury. Am J Physiol. 1999; 277:C320-9. | Article | PubMed

21. Tunstead JR, Thomas $M$ and Hornsby PJ. Early events in the formation of a tissue structure from dispersed bovine adrenocortical cells following transplantation into scid mice. J Mol Med (Berl). 1999; 77:666-76. | Article I PubMed

22. Kuang S, Charge SB, Seale P, Huh M and Rudnicki MA. Distinct roles for Pax7 and Pax3 in adult regenerative myogenesis. J Cell Biol. 2006 172:103-13. | Article | PubMed Abstract | PubMed Full Text

23. Shireman PK, Contreras-Shannon V, Reyes-Reyna SM, Robinson SC and MCManus LM. MCP-1 parallels inflammatory and regenerative responses in ischemic muscle. J Surg Res. 2006; 134:145-57. | Article | PubMed

24. Ricardo SD, van Goor $\mathrm{H}$ and Eddy AA. Macrophage diversity in renal injury and repair. J Clin Invest. 2008; 118:3522-30. | Article | PubMed Abstract | PubMed Full Text

25. Badylak SF, Valentin JE, Ravindra AK, McCabe GP and Stewart-Akers AM. Macrophage phenotype as a determinant of biologic scaffold remodeling. Tissue Eng Part A. 2008; 14:1835-42. | Article I PubMed

26. Brown BN, Valentin JE, Stewart-Akers AM, McCabe GP and Badylak SF. Macrophage phenotype and remodeling outcomes in response to biologic scaffolds with and without a cellular component. Biomaterials. 2009; 30:1482-91. | Article | PubMed Abstract | PubMed Full Text

27. Megeney LA, Kablar B, Garrett K, Anderson JE and Rudnicki MA. MyoD is required for myogenic stem cell function in adult skeletal muscle. Genes Dev. 1996; 10:1173-83. | Article | PubMed

28. Ludolph DC and Konieczny SF. Transcription factor families: muscling in on the myogenic program. FASEB J. 1995; 9:1595-604. | Article | PubMed

29. Merritt EK, Hammers DW, Tierney M, Suggs LJ, Walters TJ and Farrar RP. Functional assessment of skeletal muscle regeneration utilizing homologous extracellular matrix as scaffolding. Tissue Eng Part A. 2010; 16:1395-405. | Article | PubMed

30. De Bari C, Dell'Accio F, Vandenabeele F, Vermeesch JR, Raymackers JM and Luyten FP. Skeletal muscle repair by adult human mesenchymal stem cells from synovial membrane. J Cell Biol. 2003; 160:909-18. | Article | PubMed Abstract | PubMed Full Text

31. Pecanha R, Bagno LL, Ribeiro MB, Robottom Ferreira AB, Moraes MO, Zapata-Sudo G, Kasai-Brunswick TH, Campos-de-Carvalho AC Goldenberg RC and Saar Werneck-de-Castro JP. Adipose-derived stemcell treatment of skeletal muscle injury. J Bone Joint Surg Am. 2012; 94:609-17. | Article | PubMed

32. Dezawa M, Ishikawa H, Itokazu Y, Yoshihara T, Hoshino M, Takeda S, Ide $\mathrm{C}$ and Nabeshima Y. Bone marrow stromal cells generate muscle cells and repair muscle degeneration. Science. 2005; 309:314-7. | Article | PubMed

33. Badylak SF, Freytes DO and Gilbert TW. Extracellular matrix as a biological scaffold material: Structure and function. Acta Biomater. 2009; 5:1-13. | Article | PubMed

34. Osses $\mathrm{N}$ and Brandan $\mathrm{E}$. ECM is required for skeletal muscle differentiation independently of muscle regulatory factor expression. Am J Physiol Cell Physiol. 2002; 282:C383-94. | Article | PubMed

35. Hodde JP, Record RD, Liang HA and Badylak SF. Vascular endothelial growth factor in porcine-derived extracellular matrix. Endothelium. 2001; 8:11-24. | Article | PubMed

36. Voytik-Harbin SL, Brightman AO, Kraine MR, Waisner B and Badylak SF. Identification of extractable growth factors from small intestinal submucosa. J Cell Biochem. 1997; 67:478-91. | Article I PubMed

37. Hodde JP, Ernst DM and Hiles MC. An investigation of the long-term bioactivity of endogenous growth factor in OASIS Wound Matrix. $J$ Wound Care. 2005; 14:23-5. I Article I PubMed

38. Robinson KA, Li J, Mathison M, Redkar A, Cui J, Chronos NA, Matheny RG and Badylak SF. Extracellular matrix scaffold for cardiac repair. Circulation. 2005; 112:I135-43. | Article | PubMed

39. Eweida A, Saad M, Gabr E, Marei M and Khalil MR. Cultured keratinocytes on urinary bladder matrix scaffolds increase angiogenesis and help in rapid healing of wounds. Adv Skin Wound Care. 2011; 24:268-73. | Article | PubMed

40. Agrawal V, Brown BN, Beattie AJ, Gilbert TW and Badylak SF. Evidence of innervation following extracellular matrix scaffold-mediated remodelling of muscular tissues. J Tissue Eng Regen Med. 2009; 3:590600. | Article | PubMed Abstract | PubMed Full Text

41. Yan Z, Choi S, Liu X, Zhang M, Schageman JJ, Lee SY, Hart R, Lin L, Thurmond FA and Williams RS. Highly coordinated gene regulation in mouse skeletal muscle regeneration. J Biol Chem. 2003; 278:8826-36. | Article | PubMed

\section{Citation:}

Song J, Hornsby P, Stanley M, AbdelFattah KR and Wolf SE. Porcine urinary bladder extracellular matrix activates skeletal myogenesis in mouse muscle cryoinjury. J Regen Med Tissue Eng. 2014; 3:3. http://dx.doi.org/10.7243/2050-1218-3-3 